\title{
Light-dependent development of two competitive species (Rubus idaeus, Cytisus scoparius) colonizing gaps in temperate forest
}

\author{
Noémie GAUdiO $^{1}$, Philippe BALANDIER ${ }^{2 *}$, André MARQUiER ${ }^{1}$ \\ ${ }^{1}$ UMR547 PIAF, INRA, Univ. Blaise Pascal, 63100 Clermont-Ferrand, France \\ ${ }^{2}$ Cemagref, UR Écosystèmes Forestiers, Domaine des Barres, 45290 Nogent-sur-Vernisson, France
}

(Received 31 January 2007; version revised 18 April 2007; accepted 8 June 2007)

\begin{abstract}
Forest regeneration can be inhibited by competition for environmental resources (water, nutrients, light) between tree seedlings and some competitive species that are generally light-demanding species developing in gaps. The study's aim was to quantify the development of two competitive species (Rubus idaeus and Cytisus scoparius) present in the chaîne des Puys, France, relatively to light in gaps inside Picea abies stands. On 29 transects linking the stand to the gap centre (223 points), light intensity was measured ( $0-80 \%$ of relative light) and floristic measurements (cover and height of the different species) were done. Development of both competitive species is positively connected to light, with a bell-shaped curve with a maximum of $40-50 \%$ for $R$. idaeus and a quite constant increase to $80 \%$ (maximum of light recorded in the experimentation) for C. scoparius. These results are discussed relatively to understorey vegetation management in order to favour forest regeneration.
\end{abstract}

regeneration / light / understorey vegetation / competition

Résumé - Croissance de deux espèces compétitrices (Rubus idaeus, Cytisus scoparius) colonisatrices des trouées en forêt tempérée selon la disponibilité en lumière. En forêt, la compétition pour la captation des ressources (eau, nutriments, lumière) entre certaines plantes très colonisatrices et les jeunes arbres peut mettre en péril la régénération forestière. Ces espèces sont généralement héliophiles et se développent donc dans les trouées, environnements également favorables aux semis. Le but de l'étude était de quantifier le développement de deux espèces colonisatrices (Rubus idaeus et Cytisus scoparius) de la chaîne des Puys (France) en fonction de l'intensité lumineuse dans des trouées situées en forêt d'épicéas. Des mesures de lumière ont été réalisées sur 29 transects reliant l'intérieur du peuplement au centre d'une trouée (223 points au total, 0-80\% d'éclairement relatif) en parallèle à des mesures floristiques (taux de recouvrement et hauteur des différentes espèces). Les deux espèces répondent à la lumière, selon une courbe en cloche avec un maximum à 40-50\% pour $R$. idaeus et une augmentation quasi linéaire jusqu'à $80 \%$ (maximum mesuré dans l'expérimentation) pour $C$. scoparius. Ces résultats sont discutés en terme de gestion de la végétation forestière pour favoriser la régénération.

régénération / lumière / végétation de sous-bois / compétition

\section{INTRODUCTION}

Forest durability is ensured by tree regeneration. Forest stand renewal requires favourable conditions [19] at all the steps of tree development and the forest cycle, i.e. seed production, seed dormancy release, seed germination, seedling establishment and tree growth. Seedling establishment and growth is one of the most critical stages because it is particularly sensitive to shortages of environmental resources (light, nutrients and water) $[7,14]$. The vegetation in the forest understorey can compete for resources and so reduce tree seedling growth $[2,11]$. This is particularly the case of fast-growing opportunistic and often monopolistic species that grow in gaps, such as Pteridium aquilinum, Calluna vulgaris, Rubus fruticosus, $R$. idaeus, Cytisus scoparius, Epilobium angustifolium, etc. They can rapidly deplete resources and stunt tree seedling growth. Some species compete either for nutrients and water, e.g. perennial grasses with a dense root system [4], and some

*Corresponding author: philippe.balandier@cemagref.fr for light, e.g. Rubus idaeus or Cytisus scoparius through their dense cover [2,11].

However, their growth is often much more severely conditioned by shade than that of tree seedlings. Therefore to secure regeneration the forest manager has to adjust light availability by thinning to a degree that allows tree seedling to become established and grow, though not at the maximum rate, but still impedes the growth of competitive species [23]. This is known as indirect facilitation: the direct negative impact of shade on tree seedlings is lower than the direct positive effect of reducing competitive species growth [18]. Although the harmful role of competitive species on tree seedlings is well known [17], the literature does not offer much information on the precise response of competitive species to light in terms of growth and development.

Here we focused on two abundant species colonizing forest gaps in the Massif Central in France - Cytisus scoparius and Rubus idaeus - that are mainly competitive for light $[2,11]$. Our objectives were (i) to quantify their height and cover in response to light, (ii) to validate the general ecological 


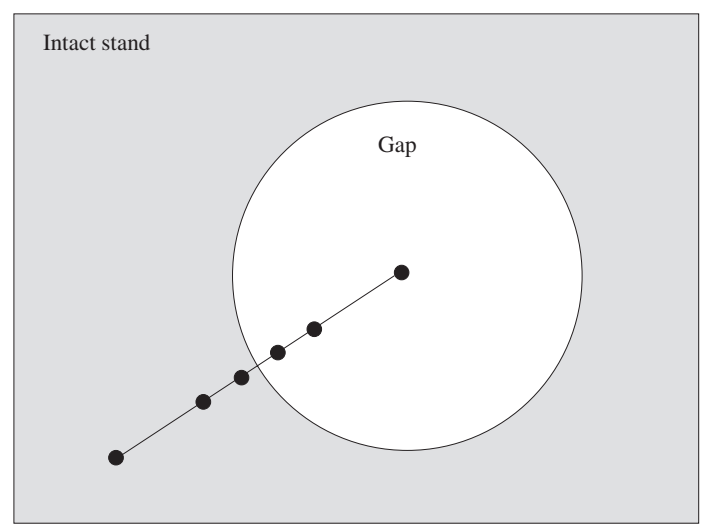

Figure 1. Schematic localization of the transect across a gap in the Picea abies stand and measurement points (black rounds). They are unequally distributed on the transect to sample the whole light variability which is maximum at the stand - gap interface.

classification (e.g. [10]) of Rubus idaeus as a medium- to highlight-demanding species and Cytisus scoparius as a high-lightdemanding species, and (iii) to draw consequences for tree regeneration.

\section{MATERIAL AND METHODS}

\subsection{Study sites}

The study was conducted in the medium-elevation uplands of the Massif Central in France, on three sites located in the Chaîne des Puys ( $45^{\circ} 38^{\prime}-45^{\circ} 55^{\prime} \mathrm{N}, 2^{\circ} 47^{\prime}-3^{\circ} 4^{\prime}$ E): Puys des Goules, Laschamps and Saulzet-le-froid. This volcanic region of mean altitude $900 \mathrm{~m}$ is characterized by an upland climate, with mean annual temperature $7{ }^{\circ} \mathrm{C}$ and means annual rainfall $1000 \mathrm{~mm}$ [22]. Soils are brown, on a substrate of basaltic ash-fall deposits or lava blocks, and relatively fertile with a mean $\mathrm{pH}_{\text {water }}$ of 6 . Picea abies is an introduced species in the region but is largely represented and forms numerous vast pure stands. Many of those suffered from the windstorm of December 1999 that created many gaps of ranging sizes. We selected a Picea abies stand on each site. In order to reduce variability other than light, they were chosen with the same main characteristics. They were all 50-year-old, with a mean DBH of $30 \mathrm{~cm}$, and a mean height of $20 \mathrm{~m}$. Soil depth was approximately $60 \mathrm{~cm}$ with no mineral deficiency.

\subsection{Experimental design}

A total of 29 transects were established in gaps inside these stands. Gaps were selected for the presence of at least one of the two competitive species (Cytisus scoparius or Rubus idaeus) and importance was not given to the size of the gap but to sample a light range as wide as possible. Hence gap size ranged approximately from $20 \mathrm{~m}$ to $100 \mathrm{~m}$. A transect connected a point located inside intact stand (darker point, no vegetation) to a point located in the middle of a gap (the more lighted, heavy vegetation), to use the light gradient at the stand - gap interface (Fig. 1). A different number of points were marked according to the gap size with more points at the stand - gap interface where vegetation cover changed very rapidly. Hence the distance between two points varied from 2 to $4 \mathrm{~m}$. The number of points for a transect varied from 5 (little gaps) to 12 (large gaps) representing a total of 223 points for the 3 sites.

\subsection{Light and vegetation measurements}

On each point of a transect, the quantum of photosynthetically active radiation (PAR, $400-700 \mathrm{~nm}$, in $\mu \mathrm{mol} \mathrm{m} \mathrm{m} \mathrm{s}^{-2}$ ) was measured above understorey competitive vegetation with a point light sensor (SOLEMS, PAR/CBE80 model). At the same time incident PAR was measured with the same type of sensor in an open field near the different selected gaps. Measurements were made over a 24-h period to factor in the daily solar pathway in the sky. Transmittance was then calculated as the ratio $(\times 100)$ of values measured in the forest understorey to incident values, so eliminating the effect of different weather conditions on different measurement days [3,16].

A botanical survey was carried out inside a radius of $50 \mathrm{~cm}$ around each light measurement point. In particular, the cover (\% of the circular area occupied by the vertical projection of the foliage of a plant group belonging to the same species) of all species, and especially $R$. idaeus and C. scoparius, was visually estimated. The mean height of each species was also measured with a measuring stick considering the average between the tallest and the smallest individuals. Some Picea abies seedlings were present but they did not overtop the vegetation.

Available soil water content (AWC) was calculated for each transect from soil texture, structure, and depth [1].

\subsection{Data analysis}

Data were analysed using Statgraphics ${ }^{\circledR}$ software. General links between the different variables (height and cover of the two colonizing species, transmittance, and AWC) were first explored using Spearman rank correlations. As there were some significant differences among sites in vegetation cover and height (Tab. I), it was not possible to analyze globally the relationships between transmittance and cover or height with a regression analysis, the site effect confusing the relationship. Hence a multi-factors ANOVA with transmittance and site as factors was used. Transmittance $(0-100 \%)$ was divided in ten classes of the same range $(0-10,10-20$, etc.). The normality of variables was checked graphically. When relevant ( $p$-value $<0.05$ ), means were separated by multiple range test (LSD), which allowed to determine the light classes with statistically higher vegetation development. To test for a possible competition effect of the other plant species present on a point of measurement on the development of Rubus idaeus, a competition index was calculated as the relative Rubus height in comparison with the height of the most developed plant. Hence an index greater than one means that Rubus was not overtopped by other species. To test for the potential effect of plant competition, the index was used as a co-variable in an ANCOVA with transmittance and site as factors.

\section{RESULTS}

Cover and height of both Rubus idaeus and Cytisus scoparius varied among sites and this variation was significant for Cytisus cover and height and Rubus height (Tab. I). They 
Table I. Cover and height of Rubus idaeus and Cytisus scoparius in gaps of Picea abies stands in central France and links with transmittance.

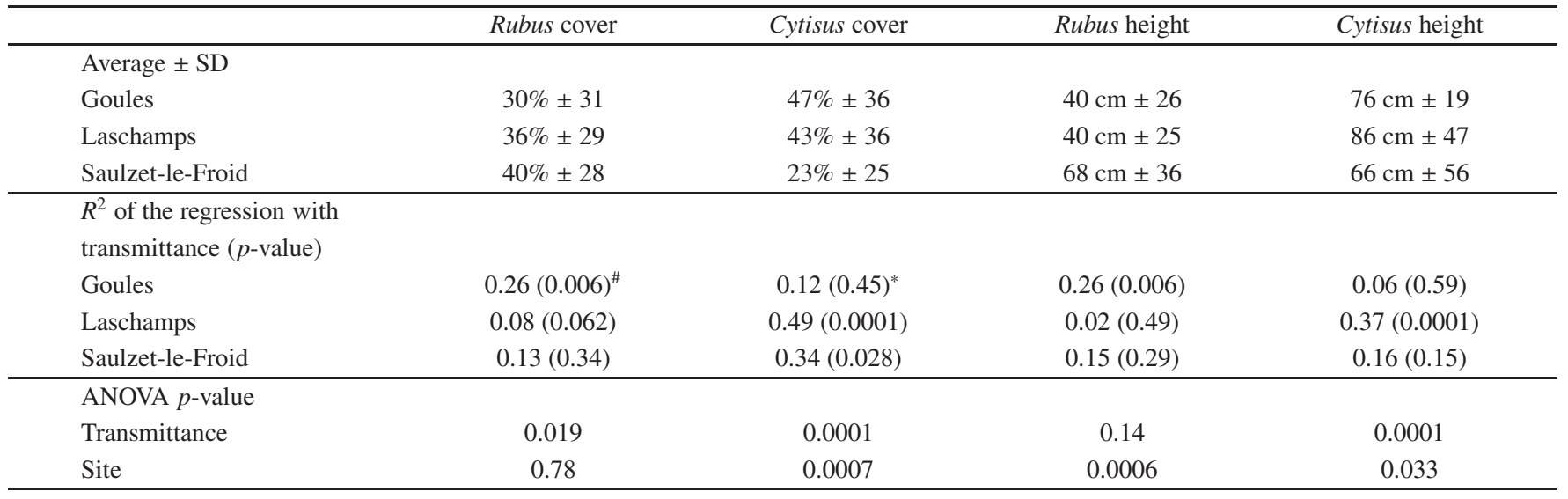

\# A quadratic regression was used for Rubus idaeus; * a linear regression was used for Cytisus scoparius.

(a)

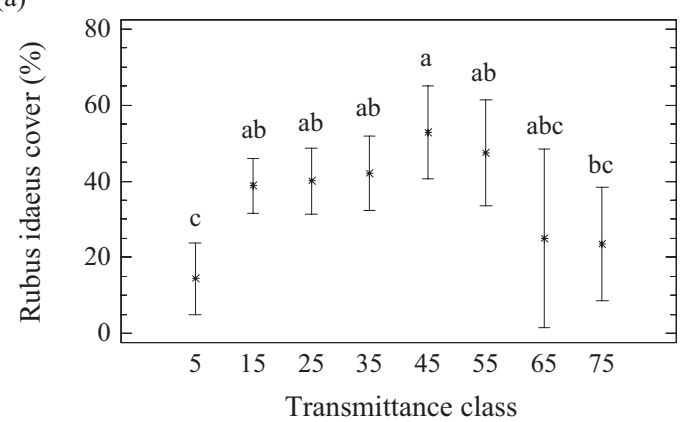

(b)

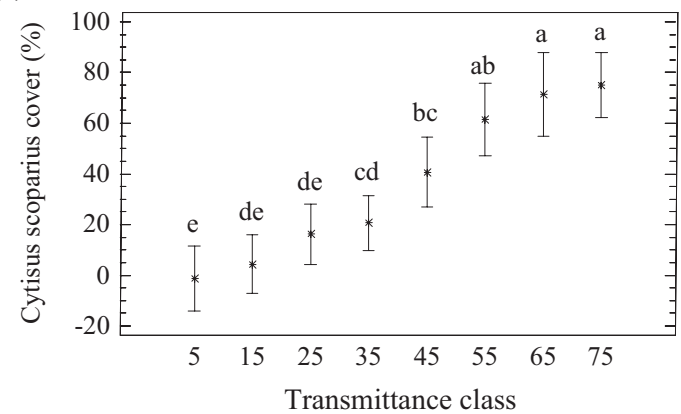

Figure 2. Rubus idaeus (a) and Cytisus scoparius (b) mean cover according to transmittance (divided by classes of $10 \%$, the middle of the interval is given on the $x$-axis) and LSD interval at 95\%. Significant different means are separated by different letters.

also varied greatly for a given site, variations significantly related to transmittance for most sites, with a quadratic regression for Rubus and a linear regression for Cytisus (Tab. I). Taking into account the site effect in the ANOVA, transmittance had a significant effect on the cover of both Rubus and Cytisus. A bell-shaped curve was recorded for Rubus cover according to light (Fig. 2a), whereas a quite constant increase was observed for Cytisus (Fig. 2b). The maximum cover was (a)

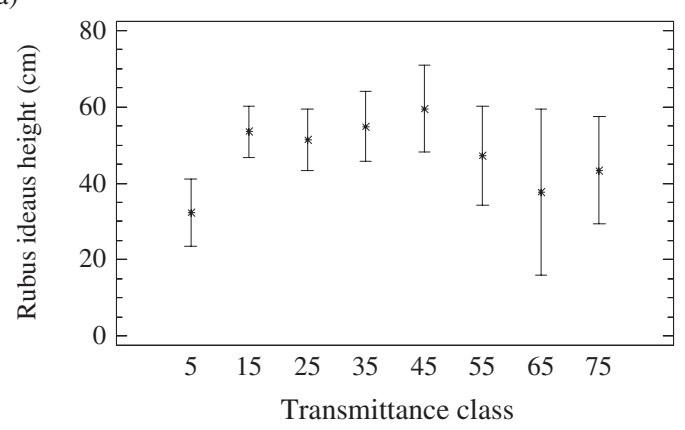

(b)

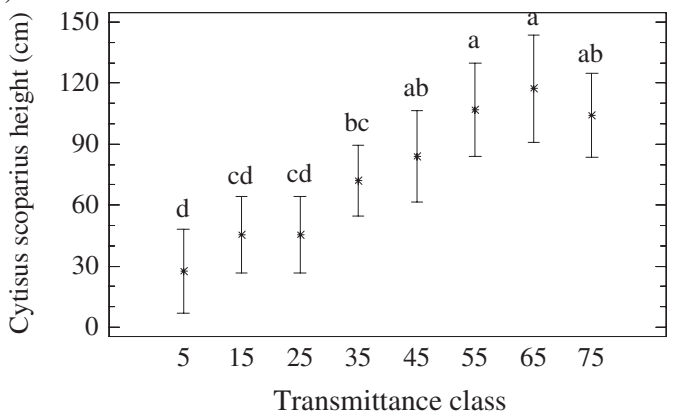

Figure 3. Rubus idaeus (a) and Cytisus scoparius (b) mean height according to transmittance (divided by classes of $10 \%$, the middle of the interval is given on the $x$-axis) and LSD interval at $95 \%$. Significant different means are separated by different letters.

at 40-50\% transmittance for Rubus and 60-80\% for Cytisus (maximum transmittance recorded in our experiment). Transmittance seemed to have no influence on Rubus height (Tab. 1, Fig. 3a), whereas a highly significant increase in height with transmittance was noted for Cytisus (Tab. I, Fig. 3b). Available soil water content (AWC) varied little from 60 to $80 \mathrm{~mm}$ whatever the considered site and had no significant effect on cover or height of both species. 


\section{DISCUSSION}

Cover was positively related to light for both colonizing species, but maxima were not obtained at the same light intensity; about $45 \%$ for Rubus idaeus and more than $60 \%$ for Cytisus scoparius. Also, Rubus cover followed a bell-shaped curve according to light, indicating that below or above this maximum value its cover was reduced. This was not the case of Cytisus, which showed a constant increase in cover with light (at least to $80 \%$, the highest value recorded in our experiment). This is probably due to the nature of each species. It could be suggested that Cytisus, because of its leguminous nature, needs more energy, and so more light, to realize the nitrogen fixation. These results are therefore consistent with the general ecological classification of Cytisus as a high-lightrequiring species and Rubus as more a medium-light-requiring species than a high-light-requiring one. Ellenberg's light indicator values are 7 and 8 (on a scale of 9) for Rubus idaeus and Cytisus scoparius, respectively [10]. The present study suggests a higher difference in light requirement between both species. The classification of Landolt [15] seems more in correspondence with our data, with a value of 3 (on a scale of 5) for Rubus idaeus, namely a medium-light-requiring species (no data available for Cytisus). Whatever the case, some studies demonstrated that indicator values must be used carefully outside their zones of validation (central Europe for Ellenberg's indicator and Switzerland for Landolt's ones) [13] or in recent woodlands as in our case [9]. The decrease of Rubus cover at high light would also be interpreted as an effect of competition from the other species present in the direct vicinity of Rubus. However including a competition index based on the relative height of Rubus in comparison with competitors (see Sect. 2) as a co-variable in an ANCOVA with transmittance and site as factors still gave a significant effect of transmittance on Rubus cover ( $p=0.0064$ ) with a bell-shaped response. An ANOVA made only on the points where Rubus was dominant (Rubus height/ plants height > 1) gave also the same results, i.e. a decrease of Rubus cover at high light. Therefore such a competition effect to explain Rubus cover decrease at high light is unlikely. However we recognize that experiments in controlled conditions are needed to clarify Rubus response to light.

Other factors not included in this experiment play a nonnegligible role in controlling Rubus and Cytisus growth, and probably confounded the influence of light. Calculated available soil water content (AWC) was not different among the different transects and sites, but temperatures and nutriments can also play an important role [8]. Also genotype [12] or age $[21,22]$, connected to vegetation dynamics after the gap creation, may have influenced the results.

Tree regeneration is strongly influenced by light availability, and both Rubus and Cytisus are able to intercept a large amount of incident light [2]. Some data reported an interception of more than $90 \%$ of incident light for mature and dense Cytisus canopies [22] while an interception of more than $80 \%$ is very likely for Rubus which can have a LAI greater than 2.8 [2]. In those conditions, only seedlings of shade-tolerant or mid-tolerant tree species can survive under dense cover of both species. Two shade-tolerant species are common in the study area, Abies alba and Fagus sylvatica, and a mid-tolerant species, Picea abies. Even if shade-tolerant species are able to survive in very low light availability, they grow better with increasing light $[5,6,24]$. Therefore a compromise is to be found between a light value that sufficiently reduces competitive vegetation development while allowing a non negligible growth of tree regeneration [20]. Accordingly, our findings suggest that light availability in forests should be reduced to below $30 \%$ to prevent more than $20 \%$ Cytisus scoparius cover (about $50 \mathrm{~cm}$ height). In those conditions the three species cited above could correctly grow. However, transmittance should be reduced much more if the goal is to prevent Rubus idaeus, which presents $40 \%$ cover (about $50 \mathrm{~cm}$ height) when light only exceeds $10 \%$. In those conditions, only the shade-tolerant species should be considered. However we obviously need to specify the light interception relative to Cytisus or Rubus cover to refine silviculture recommendations.

Acknowledgements: This work was supported by a grant from the national ECOGER program.

\section{REFERENCES}

[1] Baise D., Jabiol B., Guide pour la description des sols, INRA, Paris, France, 1995.

[2] Balandier P., Collet C., Miller J.H., Reynolds P.E., Zedaker S.M., Designing forest vegetation management strategies based on the mechanisms and dynamics of crop tree competition by neighboring vegetation, Forestry 79 (2006) 3-27.

[3] Balandier P., Sonohat G., Sinoquet H., Varlet-Grancher C., Dumas Y., Characterisation, prediction and relationships between different wavebands of solar radiation transmitted in the understorey of evenaged oak (Quercus petraea, Q. robur) stands, Trees 20 (2006) 363370.

[4] Coll L., Balandier P., Picon-Cochard C, Morphological and physiological responses of beech (Fagus sylvatica) seedlings to grassinduced belowground competition, Tree Physiol. 24 (2004) 45-54.

[5] Coll L., Balandier P., Picon-Cochard C., Prévosto B., Curt T., Competition for water between beech seedlings and surrounding vegetation in different light and vegetation composition conditions, Ann. For. Sci. 60 (2003) 593-600.

[6] Curt T., Coll L., Prévosto B., Balandier P., Kunstler G., Plasticity in growth, biomass allocation and root morphology in beech seedlings as induced by irradiance and herbaceous competition, Ann. For. Sci. 62 (2005) 51-60.

[7] Davis M.A., Wrage K.J., Reich P.B., Tjoelker M.G., Shaeffer T., Muermann C., Survival, growth, and photosynthesis of tree seedlings competing with herbaceous vegetation along a waterlight-nitrogen gradient, Plant Ecol. 145 (1999) 341-350.

[8] Diquélou S., Rozé F., Establishment of broom, impact of previous land use and soil dynamics in old field (Brittany, France), C.R. Acad. Sci. 322 (1999) 705-715.

[9] Dzwonko Z., Assessment of light and soil conditions in ancient and recent woodlands by Ellenberg indicator values, J. Appl. Ecol. 38 (2001), 942-951.

[10] Ellenberg H., Weber H.E., Düll R., Wirth V., Werner W. et Paulißen D., Zeigerwerte von Pflanzen in Mitteleuropa, Verlag Goltze, Göttingen, 1992, 248 p.

[11] Frochot H., Armand G., Gama A., Nouveau M., Wehrlen L., La gestion de la végétation accompagnatrice : état et perspective, Rev. For. Fr. LIV. 6 (2002) 505-520. 
[12] Graham J., Marshall B., Squire G.R., Genetic differentiation over a spatial environmental gradient in wild Rubus idaeus populations, New Phytol. 157 (2003) 667-675.

[13] Hill M.O., Roy D.B., Mountford J.O., Bunce R.G.H., Extending Ellenberg's indicator values to a new area: an algorithmic approach, J. Appl. Ecol. 37 (2000) 3-15.

[14] Kozlowski T.T., Physiological ecology of natural regeneration of harvested and disturbed forest stands: implications for forest management, For. Ecol. Manage. 158 (2000) 195-221.

[15] Landolt E., Ökologische Zeigerwerte zur Schweizer Flora, Veröffentlichungen des Geobotanischen Institutes der ETH, Stiftung Rübel 64 (1977) 1-208.

[16] Lieffers V.J., Messier C., Stadt K.J., Gendron F., Comeau P.G., Predicting and managing light in the understory of boreal forests, Can. J. For. Res. 29 (1999) 796-811.

[17] Nambiar E.K.S., Sands R., Competition for water and nutrients in forests, Can. J. For. Res. 23 (1993) 1955-1968.

[18] Pages J.-P., Michalet R., A test of the indirect facilitation model in a temperate hardwood forest of the northern French Alps, J. Ecol. 91 (2003) 932-940.
[19] Paluch J.G., The influence of the spatial pattern of trees on forest floor vegetation and silver fir (Abies alba Mill.) regeneration in uneven-aged forests, For. Ecol. Manage. 205 (2005) 283-298.

[20] Paquette A., Bouchard A., Cogliastro A., Successful under-planting of red oak and black cherry in early-successional deciduous shelterwoods of North America, Ann. For. Sci. 63 (2006) 823-831.

[21] Paynter Q., Downey P.O., Sheppard A.W., Age structure and growth of the woody legume weed Cytisus scoparius in native and exotic habitats: implications for control, J. Appl. Ecol. 40 (2003) 470-480.

[22] Prévosto B., Robert A., Coquillard P., Development of Cytisus scoparius $\mathrm{L}$. at stand and individual level in a mid-elevation mountain of the French Massif Central, Acta Oecol. 25 (2004) 73-81.

[23] Schütz J.P., Opportunistic methods of controlling vegetation, inspired by natural plant succession dynamics with spatial reference to natural outmixing tendencies in a gap regeneration, Ann. For. Sci. 61 (2004) 149-156.

[24] Stancioiu P.T., O'Hara K.L., Regeneration growth in different light environments of mixed species, multiaged, mountainous forests of Romania, Eur. J. For. Res. 125 (2006) 151-162. 